\title{
Dietary Nitrate Acutely and Markedly Increased Exhaled Nitric Oxide in a Cystic Fibrosis Case
}

\author{
Conor P. Kerley, BSc; Emma Kilbride, BSc; Peter Greally, MD; and Basil Elnazir, MD
}

\begin{abstract}
Airway nitric oxide (NO) is a ubiquitous signaling molecule with bronchoprotective, anti-inflammatory, and anti-infective roles. Cystic fibrosis (CF) is a chronic lung condition associated with deceased exhaled NO. Strategies to increase exhaled NO in CF have yielded inconsistent results. A potential new method of increasing systemic NO involves ingestion of dietary, inorganic nitrate which is reduced to nitrite and NO. We present the case of a 12-year-old, athletic boy with CF who demonstrated acute but marked increases in exhaled $\mathrm{NO}$ following dietary nitrate consumption compared to placebo
\end{abstract}

Keywords: Cystic fibrosis; Dietary nitrate; Exhaled nitric oxide; Nitrite

$\mathrm{N}$ itric oxide (NO) is a ubiquitous signaling molecule with multiple systemic and airway roles. Cystic fibrosis (CF) is a chronic lung condition that is associated with decreased fraction of exhaled $\mathrm{NO}(\mathrm{FeNO}) \cdot{ }^{1-4}$

The impact of decreased FeNO in CF is unclear. However, potentially relevant to $\mathrm{CF}$, NO has bronchoprotective, antiinflammatory, and anti-infective roles as well as effects on ion transport ${ }^{5}$ and ciliary motility. ${ }^{6}$ Interestingly, pulmonary function in CF patients is positively correlated to airway $\mathrm{NO}^{7}$ and sputum NO metabolites, ${ }^{8}$. Further, NO deficiency contributes to impairment of airway relaxation in a murine model of $\mathrm{CF} .{ }^{1}$ Therefore, increasing NO levels may be of functional importance in CF. Strategies to increase FeNO in CF have included inhaled NO, L-arginine, and PDE5 inhibitors (eg, sildenafil), but these have yielded inconsistent safety and efficacy profiles (Table 1).

Until recently, it was thought that the only pathway for NO synthesis in vivo was via oxidation of L-arginine in the presence of oxygen catalyzed by NO synthase (NOS) enzymes. However, recently an alternative pathway for in vivo $\mathrm{NO}$ synthesis has been discovered whereby inorganic nitrate is reduced by oral bacteria to nitrite. This nitrite can be further reduced to NO enzymatically and non-enzymatically. ${ }^{9}$ Dietary nitrate is now recognized as an additional and very significant source of $\mathrm{NO}$, whereby a single serving of a nitrate-rich vegetable (eg, spinach) contains more nitrate than what is endogenously formed by all three NOS isoforms

Corresponding Author: Conor P. Kerley, BSc, Paediatric Respiratory Department National Children's Hospital, Tallaght, Dublin 24 IRELAND Email: conorkerley@gmail.com combined in $24 \mathrm{~h} .{ }^{9}$ Recent human intervention trials have demonstrated hypotensive and ergonomic effects of dietary nitrate in conjunction with increased blood NO metabolites among multiple healthy and clinical groups.

\section{Case Report}

We present a non-smoking, athletic (body mass index $19 \mathrm{~kg} /$ $\mathrm{m}^{2}$ ) boy, aged 12 years with CF. The patient had normal lung function $(\mathrm{FEV} 1=105 \%)$ and pancreatic sufficiency. This patient initially presented early in life with a history of recurrent chest infections and wheezy episodes. An initial sweat test chloride of $112 \mathrm{mmol} / \mathrm{L}$ and confirmatory sweat test chloride of $106 \mathrm{mmol} / \mathrm{L}$ in addition to genotype analysis (F508/c.262_263delTT) lead to a CF diagnosis at 9 months of age. Current investigations revealed a normal radiograph, dual-energy x-ray absorptiometry (DEXA), and glucose tolerance test with no recent hospital admissions or gastrointestinal symptoms. Further, the patient had no other medical history of note, including no asthma or allergy (which could influence FeNO measurement). He generally requires antibiotics every 8-12 weeks, but had no recent infection or antibiotic use and no evidence of concurrent bacterial colonization. Further, his medication regimen was stable and typical for a patient with CF (Table 2). We used a double-blind, randomized, placebo-controlled, crossover design to assess the acute impact of dietary nitrate as $140 \mathrm{ml}$ beetroot juice (BRJ, $12.9 \mathrm{mmol}$ nitrate) or $140 \mathrm{ml}$ matched,
Revised:August 2,2016

Accepted: September 6, 2016

doi: $10.3121 / \mathrm{cmr} .2016 .1320$

Funding Support: Funding for this project was provided by the Foundation of National Children's Hospital. The sponsor had no involvement in study design, date collection, analysis or interpretation, or manuscript preparation. 


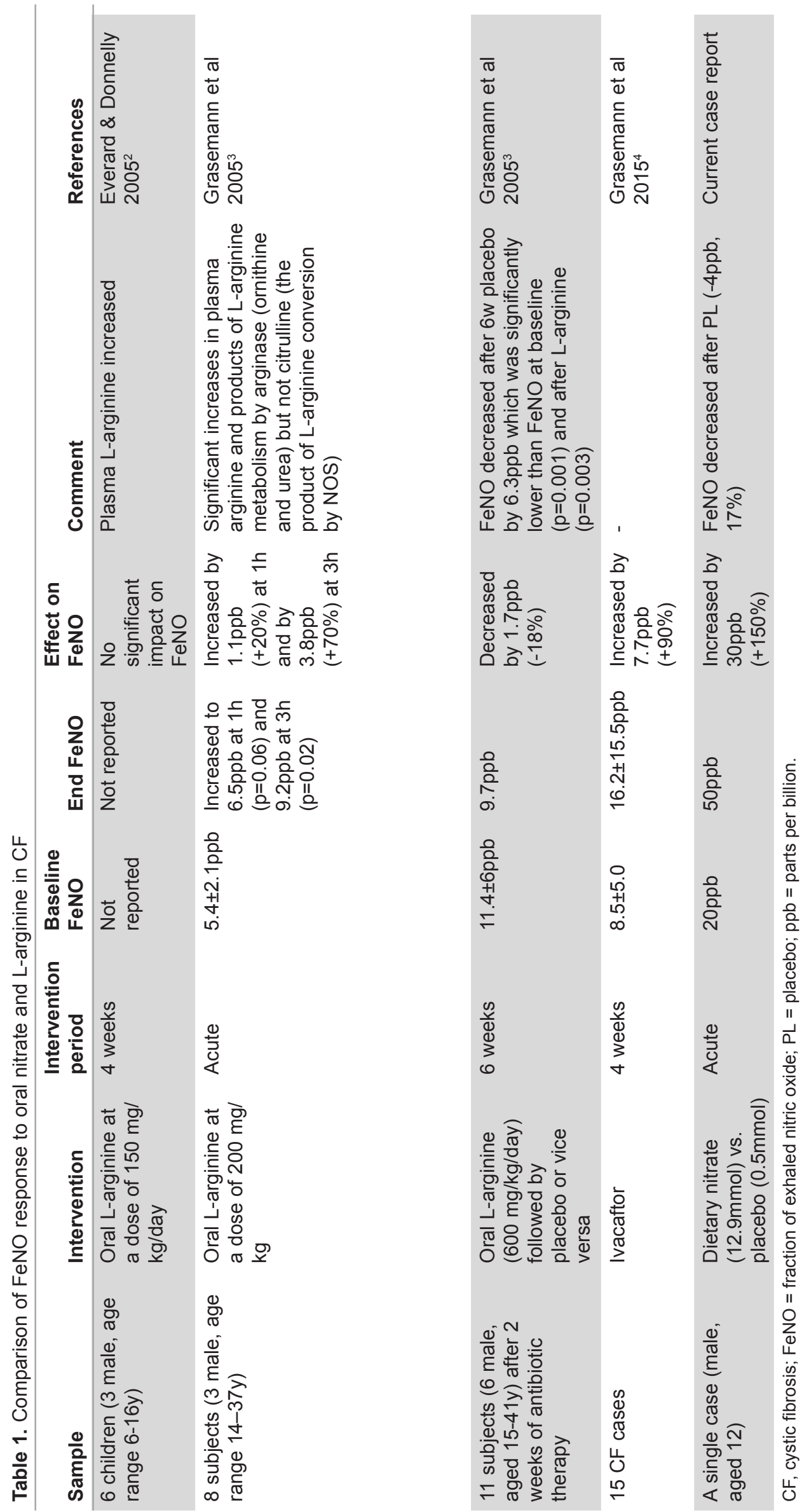


Table 2: Current medication regimen

\begin{tabular}{ll}
\hline Bronchodilators & Ventolin; Flixotide \\
PERT & Creon \\
Airway clearence aid & Nebulized pulmozyme \\
Nutritional supplements & Vitamin D; Aquadex; probiotics \\
Chest therapy & Twice daily with Acapella ${ }^{\circledR}$ device \\
\hline
\end{tabular}

PERT, pancreatic enzyme replacement therapy

nitrate-depleted beetroot juice (PL, $<0.5 \mathrm{mmol}$ ) on exhaled NO. This nitrate dose is obtainable with a diet rich in vegetables.

We conducted two clinic visits 14 days apart, where there were no relevant changes in factors known to influence NO (including diet, exercise, and medication habits). On the morning of each study visit, the patient did not use any medications or complete chest therapy, and he consumed an identical, low nitrate breakfast that was confirmed by a review with a dietitian (CPK). On both days, in an identical manner and at the same time, FeNO (NiOx MINO; Aerocrine, Sweden) and pulmonary function were assessed before and 1.5 hours after the study beverage. We added water and blackcurrant cordial (sugar- and nitrate-free) to the juice in an identical manner on both days to make it more palatable at the request of the patient. The 1.5 hour delay between baseline and post-beverage testing was to facilitate in-vivo reduction of dietary nitrate to NO. ${ }^{9}$ During this delay, the patient rested quietly in a clinic room and did not exercise, eat, drink, or take medication.

There was no effect on pulmonary function after either beverage. However, 1.5 hours following BRJ, FeNO increased by $150 \%$ (30 ppb) but decreased by $17 \%$ after PL (-4 ppb) (Figure 1 and Table 3).

This case report intervention complies with the Declaration of Helsinki and approval was granted by the research ethics committee of The National Children's Hospital. Written informed consent was provided by the mother for permission to conduct and publish this case report.

\section{Discussion}

To our knowledge, this is the first report of dietary nitrate in CF. The acute but marked FeNO increase following dietary nitrate compares favorably to other NO therapies in CF (Table 1). Interestingly, the patient studied here did not have low baseline FeNO (20ppb). Dietary nitrate as a precursor to NO seems most effective in those with dysregulated $\mathrm{NO}$, and therefore, it is possible that dietary nitrate may increase FeNO to a similar or greater extent in those with diminished baseline FeNO. Despite an increase in FeNO, there was no effect on lung function. In this context, it is noteworthy that baseline lung function was not impaired (105\%), perhaps minimizing any potential benefit.

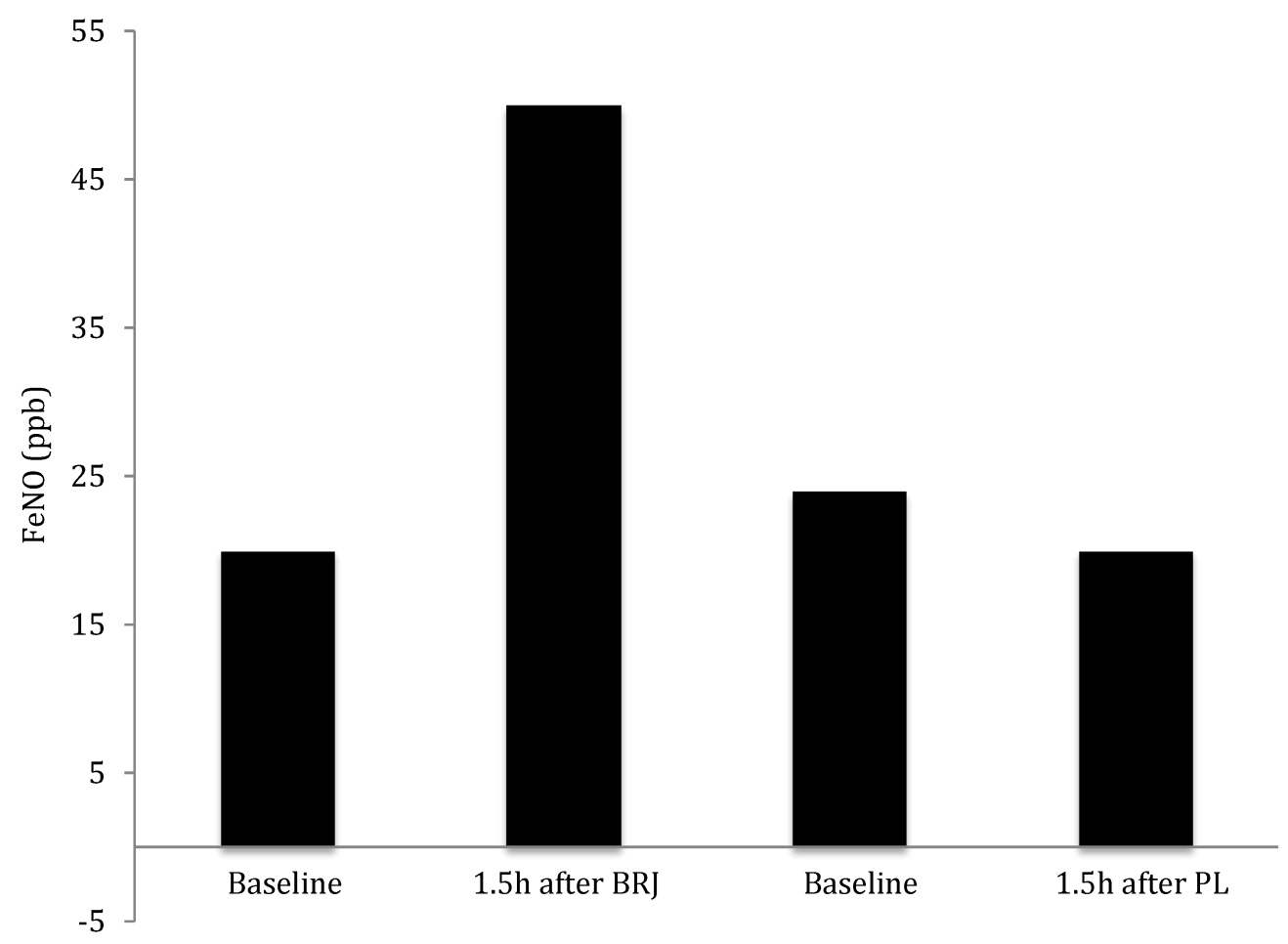

Figure 1. FeNO response to $\mathrm{BRJ}$ and $\mathrm{PL}(\mathrm{BRJ}=$ nitrate rich; $\mathrm{PL}=$ placebo, nitrate-depleted beetroot juice). 
Table 3: Pulmonary function tests

\begin{tabular}{lcc}
\hline & Day 1 & Day 2 \\
\hline Intervention & BRJ & PL \\
Baseline & 20 & 24 \\
FeNO (ppb) & $3.66(106)$ & $3.63(105)$ \\
FVC $L(\%)$ & $3.07(107)$ & $3.03(105)$ \\
FEV 1 ( (\%) & & \\
Post beverage & 50 & 20 \\
FeNO (ppb) & $3.67(106)$ & $3.52(101)$ \\
FVC $L(\%)$ & $3.06(106)$ & $2.9(101)$ \\
FEV 1 L (\%) & & \\
\hline
\end{tabular}

BRJ, nitrate-rich beetroot juice; FeNO, fraction exhaled nitric oxide; $\mathrm{FEV}_{1}$, forced expiratory volume; FVC, forced vital capacity; ppb, parts per billion; PL, placebo - nitrate-depleted beetroot juice.

Dietary nitrate is water soluble and rapidly absorbed $\sim 100 \%$ in the stomach and small intestine. There is no evidence of nitrate malabsorption in CF. Approximately 75\% of ingested nitrate is excreted via the kidneys, with the remainder concentrated in the oral gland and subsequently reduced to nitrite by tongue anaerobes. This nitrite is swallowed and then further reduced to $\mathrm{NO}$ under suitable conditions within the airway, stomach, and endothelium. After nitrate ingestion, salivary/plasma nitrate levels increase rapidly $(\sim 15 \mathrm{~m})$, peaking at $90-120 \mathrm{~m}^{13}$ The levels remain high for several hours following ingestion, after which they slowly decline, remaining elevated from baseline for $\sim 24$ hours. ${ }^{13}$ This is why we measured FeNO before and 1.5 hours after each of two beverages. Further, we measured total exhaled NO. Future studies may utilize different doses of nitrate among larger groups as well employ serial measurements of NO, nitrate, and nitrite to further our understanding of NO metabolism in response to exogenous nitrate in CF. Importantly, this patient with $\mathrm{CF}$ did not display several behaviors known to decrease the reduction of dietary nitrate to NO including use of tobacco, ${ }^{14}$ antibiotics, ${ }^{15}$ or mouthwash. ${ }^{16}$

Although, our report is limited to a single male patient with mild CF, dietary nitrate is a component of certain vegetables, appears remarkably safe, and increased FeNO to a greater extent than existing CF therapies.

Nitrate and nitrate as precursors to NO are known to have broad antimicrobial effects, ${ }^{10-12}$ including against common pathogens in CF such as Pseudomonas aeruginosa ${ }^{10,12}$ and Staphylococcus aureus. ${ }^{12}$ Further, this antimicrobial activity has been demonstrated under CF airway conditions. ${ }^{10}$

We recommend that future studies measuring FeNO are aware of potential confounding by dietary intake. Further the dietetic focus regarding CF typically emphasizes dietary fat with little focus on vegetable intake. We suggest the dietary modification of FeNO, including vegetable consumption in $\mathrm{CF}$, is worthy of further exploration.

\section{References}

1. Mhanna MJ, Ferkol T, Martin RJ, Dreshaj IA, van Heeckeren AM, Kelley TJ, Haxhiu MA. Nitric oxide deficiency contributes to impairment of airway relaxation in cystic fibrosis mice. Am J Respir Cell Mol Biol. 2001;24:621-626. doi:10.1165/ajrcmb.24.5.4313.

2. Everard ML, Donnelly D. A pilot study of oral 1-arginine in cystic fibrosis. J Cyst Fibros. 2005;4:67-69. doi:10.1016/j. jef.2004.10.001.

3. Grasemann H, Grasemann C, Kurtz F, Tietze-Schillings G, Vester U, Ratjen F. Oral L-arginine supplementation in cystic fibrosis patients: a placebo-controlled study. Eur Respir J. 2005;25:62-68. doi:10.1183/09031936.04.00086104.

4. Grasemann H, Gonska T, Avolio J, Klingel M, Tullis E, Ratjen F. Effect of ivacaftor therapy on exhaled nitric oxide in patients with cystic fibrosis. J Cyst Fibros. 2015;14:727-732. doi:10.1016/j.jcf.2015.07.001.

5. Kamosinska B, Radomski MW, Duszyk M, Radomski A, Man SF. Nitric oxide activates chloride currents in human lung epithelial cells. Am J Physiol. 1997;272:L1098-L1104.

6. Barnes PJ, Belvisi MG. Nitric oxide and lung disease. Thorax. 1993;48:1034-1043. doi:10.1136/thx.48.10.1034.

7. Grasemann H, Michler E, Wallot M, Ratjen F. Decreased concentration of exhaled nitric oxide (NO) in patients with cystic fibrosis. Pediatr Pulmonol. 1997;24:173-177. doi:10.1002/(SICI)1099-0496(199709)24:3<173::AIDPPUL2>3.0.CO;2-O.

8. Grasemann H, Ioannidis I, Tomkiewicz RP, de Groot H, Rubin BK, Ratjen F. Nitric oxide metabolites in cystic fibrosis lung disease. Arch Dis Child. 1998;78:49-53. doi:10.1136/ adc.78.1.49.

9. Lundberg JO, Gladwin MT, Ahluwalia A, Benjamin N, Bryan NS, Butler A, Cabrales P, Fago A, Feelisch M, Ford PC, Freeman BA, Frenneaux M, Friedman J, Kelm M, Kevil CG, Kim-Shapiro DB, Kozlov AV, Lancaster JR Jr, Lefer DJ, McColl K, McCurry K, Patel RP, Petersson J, Rassaf T, Reutov VP, Richter-Addo GB, Schechter A, Shiva S, Tsuchiya K, van Faassen EE, Webb AJ, Zuckerbraun BS, Zweier JL, Weitzberg E. Nitrate and nitrite in biology, nutrition and therapeutics. Nat Chem Biol. 2009;5:865-869. doi:10.1038/nchembio.260.

10. Yoon SS, Coakley R, Lau GW, Lymar SV, Gaston B. Karabulut AC, Hennigan RF, Hwang SH, Buettner G, Schurr MJ, Mortensen JE, Burns JL, Speert D, Boucher RC, Has- sett DJ: Anaerobic killing of mucoid Pseudomonas aerugi- nosa by acidified nitrite derivatives under cystic fibrosis airway conditions. J Clin Invest. 2006;116:436-446. doi:10.1172/ JCI24684.

11. Xia DS, Liu Y, Zhang CM, Yang SH, Wang SL. Antimicrobial effect of acidified nitrate and nitrite on six common oral pathogens in vitro. Chin Med J (Engl). 2006;119:1904 1909.

12. Major TA, Panmanee W, Mortensen JE, Gray LD, Hoglen N, Hassett DJ. Sodium nitrite-mediated killing of the major cystic fibrosis pathogens Pseudomonas aeruginosa, Staphylococcus aureus, and Burkholderia cepacia under anaerobic planktonic and biofilm conditions. Antimicrob Agents Chemother. 2010;54:4671-4677. doi:10.1128/ AAC.00379-10.

13. Webb AJ, Patel N, Loukogeorgakis S, Okorie M, Aboud Z, Misra S, Rashid R, Miall P, Deanfield J, Benjamin N, MacAllister R, Hobbs AJ, Ahluwalia A. Acute blood pressure lowering, vasoprotective, and antiplatelet properties of dietary nitrate via bioconversion to nitrite. Hypertension.

2008;51:784-790. doi:10.1161/

HYPERTENSIONAHA.107.103523. 
14. Tsuchiya M, Asada A, Kasahara E, Sato EF, Shindo M, Inoue M. Smoking a single cigarette rapidly reduces combined concentrations of nitrate and nitrite and concentrations of antioxidants in plasma. Circulation. 2002;105:1155-1157. doi:10.1161/hc1002.105935.

15. Dougall HT, Smith L, Duncan C, Benjamin N. The effect of amoxycillin on salivary nitrite concentrations: an important mechanism of adverse reactions? Br J Clin Pharmacol. 1995;39:460-462. doi:10.1111/j.1365-2125.1995.tb04479.x.

16. Petersson J, Carlström M, Schreiber O, Phillipson M, Christoffersson G, Jägare A, Roos S, Jansson EA, Persson AE, Lundberg JO, Holm L. Gastroprotective and blood pressure lowering effects of dietary nitrate are abolished by an antiseptic mouthwash. Free Radic Biol Med. 2009;46:10681075. doi:10.1016/j.freeradbiomed.2009.01.011.

\section{Author Affiliations:}

Conor P. Kerley, BSc*, $†$; Emma Kilbride, BSc*; Peter Greally, $M D^{*}$; Basil Elnazir, $M D^{*}$

*Paediatric Respiratory Department, National Children's Hospital, Dublin 24, Ireland † School of Medicine and Medical Sciences, University College Dublin, Belfield, Dublin 4, Ireland 